\title{
OS PERCALÇOS DO CRESCIMENTO NO BRASIL: A MUDANÇA ESTRUTURAL DA INDÚSTRIA E A ESPECIALIZAÇÃO DA PAUTA EXPORTADORA NO PERÍODO 2003-2010
}

\author{
ADVERSITIES FOR GROWTH IN BRAZIL: STRUCTURAL CHANGE IN \\ INDUSTRY AND EXPERTISE IN THE EXPORT AGENDA FROM 2003-2010
}

\begin{abstract}
Ana Maria Rita Milani*
RESUMO

Este artigo tem por objetivo estudar a mudança estrutural na indústria a partir da década de 1990 e suas consequências na inserção internacional da economia brasileira no período de 2003-2010. A balança comercial a partir de 2002 apresenta saldo superavitário, porém com especialização em commodities e piora das exportações de bens manufaturados. A partir de uma contextualização do período de estudo, apresenta-se a evolução do debate sobre desindustrialização, tentando analisar o comportamento dos setores industriais. Estuda-se a pauta exportadora e as possíveis causas da especialização. Considerando-se os dados ilustrativos do comportamento do crescimento e da pauta exportadora do governo Lula, sinalizam-se caminhos possíveis do debate de desenvolvimento do Brasil.
\end{abstract}

Palavras-chave: Desindustrialização. Pauta exportadora. Governo Lula. Desenvolvimento.

\begin{abstract}
This article have objetive to study estrutuctural's chance in industry since a decade of 1990 and your consequences in the international insertion of Brazil's economic in 2003-2010. The balance of trade since 2002 presents balance surplus, however with specialization in commodities and failing of exports of manufacturings goods. Beginning with context of period study, present a evolution of discussion sob desindustrialization, studyng sectors of industry. Study export basket and possibles causes of especialization. Whereas the behavior of growth and export basket of Lula's government point out road possibles of discussion development of Brazil.
\end{abstract}

Key words: Desindustrialization. Export basket. Lula’s government. Development.

\footnotetext{
* Doutora em Economia pela Universidade Federal do Rio Grande do Sul (UFRGS), mestre em Economia pela Universidade Federal da Bahia (UFBA) e graduada em Economia pela Universidad de Buenos Aires. É professora adjunta da Universidade Federal de Alagoas (UFAL). E-mail: <amilani22@ hotmail.com.>
} 


\section{Introdução}

Na década de 1990 o Brasil instituiu um novo modelo de desenvolvimento que teve como eixo de direção das políticas o ajuste estrutural. Inspirado no ideário neoliberal, esse modelo contemplava a desregulamentação, a liberalização comercial e financeira, a modificação da participação do Estado na economia, a âncora cambial, entre outras. Em vários governos, daquele período até os atuais, tem sido reformulado o modelo em diferentes pontos de sustentação, como, por exemplo, a política cambial e monetária. Entretanto, a essência dele continua a mesma até hoje: abertura comercial e financeira e políticas market-friendly. Cabe salientar que essas medidas implementadas na década de 1990 provocaram na economia um choque competitivo como decorrência da liberalização e da estabilidade monetária. O conjunto de medidas combinadas com as mudanças macroeconômicas que se seguiram ao Plano Real estabeleceu um ambiente competitivo diferente para a indústria brasileira, caracterizado pela sobrevalorização cambial, pelas taxas de juros elevadas e pela redução das barreiras à entrada de empresas estrangeiras.

No começo do novo século, como reflexo das reformas implementadas na década de 1990, o país vivencia uma mudança estrutural com início de um processo de especialização da estrutura industrial em setores de pouco dinamismo intraindustrial, como, por exemplo, em commodities. Essa tendência do perfil do desenvolvimento atual, que alguns autores, como Bresser-Pereira (2010), Oreiro e Feijó (2011), entre outros, sinalizam como processo de desindustrialização, reflete-se na concentração da pauta exportadora com produtos de baixo valor agregado.

Muito se tem debatido com relação à mudança estrutural e a liberalização comercial e sua contribuição para o processo de crescimento do país. Os adeptos a enxergam como um processo positivo que conseguiu contribuir para o crescimento econômico, considerando que as políticas de ajuste estrutural permitiram à economia brasileira introduzir novos investimentos e técnicas que melhoraram a competitividade, fundamentalmente porque a liberalização daria acesso às novas tecnologias que o país precisava para dar o up grade da pauta exportadora. Nesse sentido, os impactos da liberalização se fizeram sentir na balança comercial a partir de meados da década de 1990, quando os coeficientes de penetração das importações tiveram um aumento generalizado (MOREIRA, 1997; FONSECA; CARVALHO, 1998; HAGUENAUER; MARKWALD; POURCHET, 1997). As exportações reagiram de forma diferente com um ritmo muito inferior, tendo se configurado um impacto assimétrico entre exportações e importações. Assim, na década de 1990 a balança comercial apresentou saldos deficitários recorrentes.

Moreira e Correa (1997) salientam que a penetração das importações na indústria de transformação expandiu-se 200\% entre 1989 e 1996, elevando-se o coeficiente de penetração das importações de 4,6\% para $14 \%$. O incremento do coeficiente de importações foi acompanhado por um crescimento de $44 \%$ da participação das vendas externas na produção industrial, passando de 10,1\% para 14,5\%. Haguenauer e Markwald (1997) reestimaram tais coeficientes e chegaram a conclusões semelhantes. Ambos os trabalhos sinalizam os setores que aumentaram a penetração das importações: as indústrias de máquinas e equipamentos; de material e aparelhos eletrônicos e de comunicação; de beneficiamento, fiação e tecelagem de fibras artificiais e naturais; de automóveis; de tratores e máquinas de terraplanagem; e de equipamentos para produção e distribuição de energia elétrica, como as de maior coeficiente importado.

A partir de 2002 o saldo da balança comercial se modifica e passa a ser superavitário, mantendo essa tendência nos anos seguintes. O que pareceria ser um dado alentador do processo de crescimento transforma-se no fulcro do debate atual sobre o desenvolvimento do país: a especialização da pauta exportadora em commodities com piora na balança comercial de bens manufaturados.

Assim, este artigo tem por objetivo estudar a mudança estrutural na indústria a partir da década de 1990 e suas consequências na inserção internacional da economia brasileira no período de 2003-2010.

Além desta introdução, na segunda seção abordar-se-á a contextualização das políticas econômicas do período de estudo, fundamentalmente relacionada ao comportamento do crescimento, do investimento e do setor externo. Na terceira seção, será estudado o dinamismo dos setores industriais. Na quarta seção, o comportamento da pauta exportadora. E, por último, serão apresentadas as conclusões. 


\section{Contextualização do "governo Lula": alguns dados ilustrativos}

O Brasil, desde o começo da década de 1990, inseriu-se nos modelos de ajuste estrutural que contemplavam uma série de medidas que podem ser classificadas em dois grandes eixos: as de origem estrutural, sintetizadas na globalização internacional, que levaram a economia a uma maior abertura financeira e cambial e a uma mudança da concorrência intercapitalista, que teve como consequência um aumento do comércio e do investimento estrangeiro direito; e, por outro lado, as políticas macroeconômicas, que tinham como objetivo a estabilidade financeira por meio da gestão cambial, monetária e fiscal.

No âmbito das relações Estado-Mercado, ocorreu uma mudança no papel do Estado, tendendo à redução da sua participação na economia junto com a desregulamentação dos fluxos comerciais, produtivos e financeiros. Ou seja, com a mudança o Estado passa a ter um papel de regulador do mercado. As políticas aplicadas no governo Lula em sua essência não sofreram alteração em relação às do governo anterior. Contudo, alguns fatos conjunturais específicos as tornam diferentes, conforme observa Carneiro (2006):

O período 2003-2005, referente ao governo Lula, não se diferencia, exceto por eventuais diferenças quanto à gestão, daquele relativo aos anos 19992002, pois essas políticas tiveram como fundamento, a combinação entre o regime de metas de inflação, câmbio flutuante e postura fiscal contracionista.

Como dito anteriormente, nesta seção será abordado fundamentalmente o comportamento da economia brasileira com relação ao crescimento, aos investimentos e ao comportamento do setor externo. A escolha dessas variáveis deve-se à importância que elas têm para o entendimento do modelo atual de desenvolvimento e do padrão de crescimento que o sustenta. O modelo de ajuste estrutural, baseado no ideário neoliberal, foi incapaz de construir um caminho para o crescimento sustentado da economia brasileira, e no governo Lula esse fato não foi diferente; pelo contrário, apresenta-se como uma característica persistente.

O crescimento recente evidencia um padrão stop and go, como nos últimos 20 anos da história do
Brasil. Ilustra essa característica o Gráfico $n^{\circ} 1$. As políticas neoliberais mostram-se incapazes de construir um modelo de desenvolvimento que gere um crescimento sustentado. Para analisar como evoluiu o crescimento da economia brasileira, cuja taxa média do período situou-se ao redor de $4 \%$ a.a, detalhar-se-á o comportamento das variáveis que contribuíram para a movimentação da demanda agregada da economia.

Gráfico 1 - Evolução do crescimento do Brasil - 1996-2010

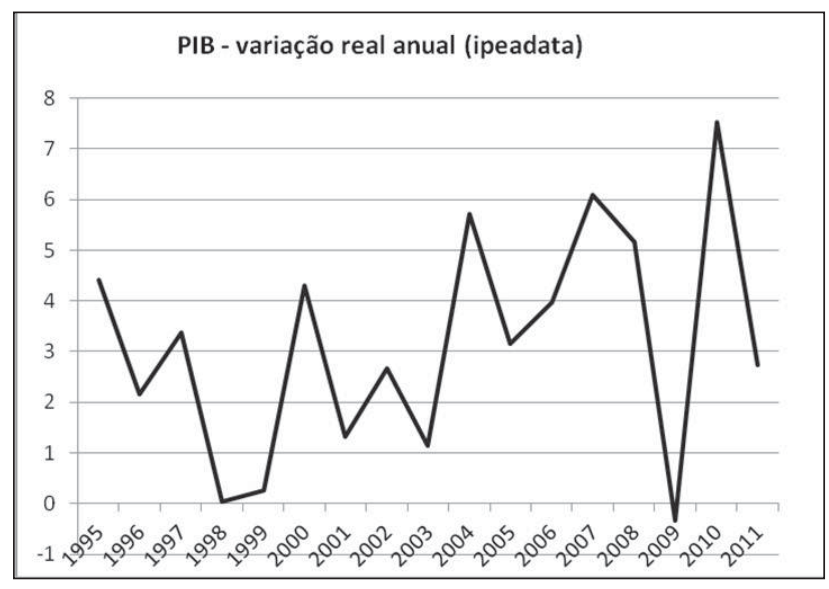

Fonte: elaboração própria, dados Ipeadata, 2011.

Ao se analisar, no período em questão, a variável investimento, observa-se que a mesma apresentou um comportamento decrescente nos últimos 25 anos. Se considerarmos o investimento medido como FBKF/PIB, nota-se que um dos períodos de maior participação foi nos anos 1970, ao alcançar $25 \%$, contra $15 \%$ dos anos de 1990 . Como assinala Paulani (2008), essa ilustração contribuiu para desfazer aquela ideia da “década perdida” dos anos de 1980, quando, na verdade, a década posterior apresentou indicador mais negativo. Na década de 1980 a economia brasileira apresentou em média um nível de 18,55\%, medido também como FBKF/PIB. O país apresentou uma pequena aceleração dessa variável em 2003, fundamentalmente pelo aumento de investimentos nos setores exportadores de commodities primárias, os quais se transformariam nos setores mais dinâmicos da indústria, a partir da metade da década de 1990. Ou seja, o aumento do investimento está relacionado a desdobramentos do aumento do comércio internacional em produtos básicos e ao perfil do modelo de desenvolvimento que se especializa nesses produtos. A capacidade de 
produção foi modificada muito lentamente, sem causar impacto na taxa de crescimento do investimento. Noutros setores, teve investimento de modernização, mas que foram específicos, para solucionar gargalos, sem provocar uma onda expansiva na economia.

Gráfico 2 - Evolução do investimento (FBKF) var. real

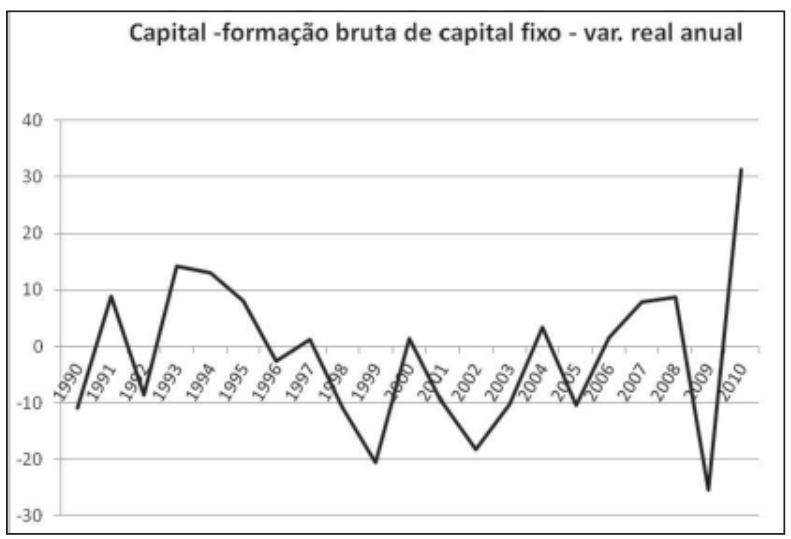

Fonte: elaboração própria, (ipeadata, 2011).

Dentro dos componentes da demanda agregada, a única variável que teve um comportamento crescente influenciando positivamente as fontes de crescimento tem sido as exportações liquidas. Ela apresenta taxas de expansão crescente desde 2002, sendo esse fenômeno visto como um fator positivo da economia brasileira. A importância do ciclo internacional não está associada a políticas de taxa de câmbio, pois a desvalorização da moeda ocorreu em 1999, mesmo porque a expansão do ciclo ocorre a despeito da apreciação da moeda que se apresenta a partir de 2003. Em linhas gerais, o ciclo de crescimento internacional pode ser atribuído ao fraco desempenho da economia doméstica (absorção interna), ao extraordinário crescimento do comércio internacional, à elevação dos preços das commodities e condições relativamente estáveis de liquidez internacional até 2008.

No Gráfico $n^{0} 3$ podemos observar a evolução do saldo comercial nos últimos vinte anos. Com o Plano Real posto em marcha, existiu uma tendência de aumento dos déficits que foi revertida no começo do século, para mostrar-se como uma característica persistente no restante do período estudado.

Gráfico 3 - Balança Comercial Brasileira - U\$S FOB (acumulado 12 meses)

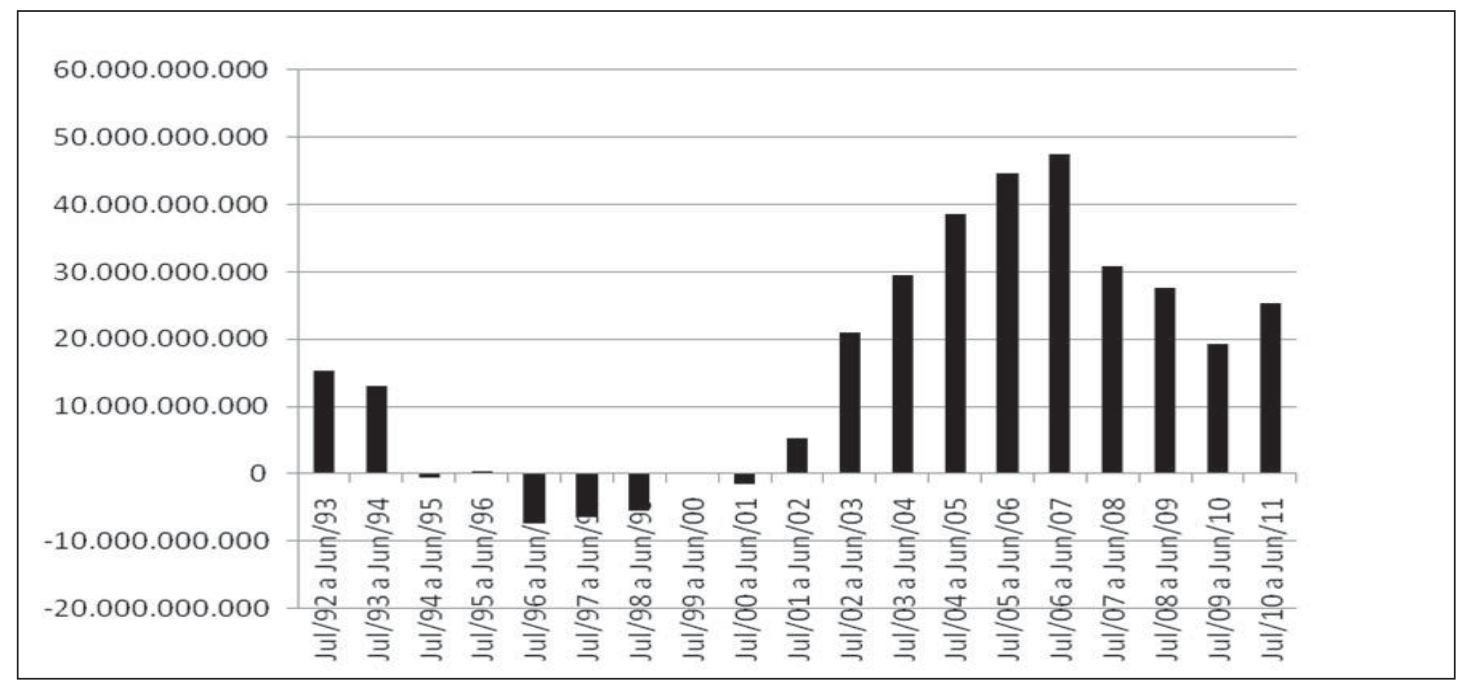

Fonte: elaboração própria, dados MDIC, (2011).

No entanto, o dinamismo apresentado pelas exportações líquidas pode ser relacionado a fatores externos que, por sua vez, reforçam o perfil tecnológico da balança comercial, qual seja: superávit em setores básicos como as commodities primárias e em setores intensivos em recursos naturais. Desde a dé- cada de 1990, o Brasil vem aumentando a participação dos produtos básicos nos saldos exportáveis, fenômeno que pode estar relacionado ao aumento dos preços no comércio internacional - por exemplo, o preço da soja em média aumentou $60 \%$-, e ao crescimento da China. O crescimento desse país também 
explica a maior participação relativa dos bens de baixa intensidade tecnológica, como o aço. O Gráfico n ${ }^{\circ}$ 4 é ilustrativo desse fenômeno.

Nessa perspectiva, o padrão de inserção internacional do Brasil começa a se concretizar com novas características a partir do começo do século XXI. Assim, Prates (2004, p.23) frisava: "O padrão de inserção internacional [...] é reflexo da reestruturação produtiva induzida pelo tripé: abertura comercial, valorização real da moeda doméstica e novas estratégias das empresas transnacionais”.

O perfil tecnológico das exportações do Brasil, caracterizado por concentração de exportações em commodities primárias e bens de baixa intensidade tecnológica, foi um dos fatores responsáveis pelo baixo dinamismo da economia nas décadas de 1980 e 1990. Como assinalado por Prates (2004), esse pífio dinamismo deve-se, em parte, às políticas comerciais protecionistas dos países centrais, que afetavam principalmente as commodities. Atualmente, existe uma conjuntura externa favorável ao perfil das exportações brasileiras, porém não se pode deixar de salientar a fragilidade estrutural que apresenta o setor exportador. Essa fragilidade relaciona-se com a vulnerabilidade das flutuações dos preços internacionais e o baixo valor agregado que esses produtos apresentam, com pouco efeito dinâmico em termos de geração de renda e emprego, afetando assim as possibilidades de crescimento no futuro. Dessa forma fica questionado o crescimento sustentado de longo prazo.

Gráfico 4 - Evolução do comércio por fator agregado

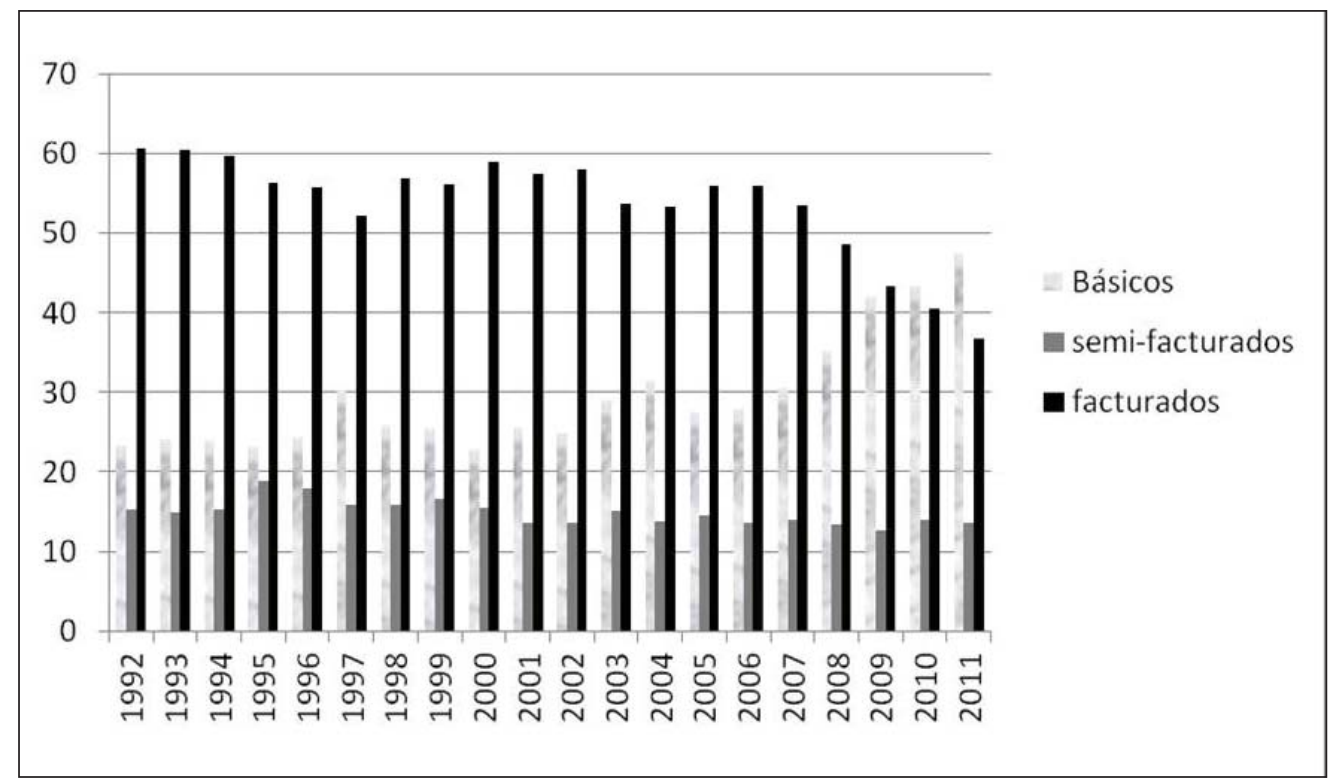

Fonte: elaboração própria, dados MDIC, 2011.

Assim, pode-se dizer que as trocas do comércio têm se mostrado desfavoráveis para o desenvolvimento, fundamentalmente porque a variável da demanda agregada que sustenta o crescimento são as exportações líquidas que apresentam pouco dinamismo com relação aos encadeamentos e elos da indústria, não gerando efeito multiplicador na economia. Essa tendência pode significar perda de emprego, importações desordenadas e uma especialização em produção de commodities: minério de ferro, soja, petróleo, biocombustíveis, carnes, etc.

Enfim, pode-se observar que a partir das políticas implementadas no Brasil a indústria sofre uma especialização regressiva, embora localizada e de forma relativa que sugere pôr em questão as possibilidades de crescimento sustentado. $\mathrm{O}$ fato mais 
gritante quanto ao padrão de especialização da indústria brasileira evidencia-se quando os dados são os desagregados apresentados na próxima seção. Esse fenômeno, junto com as condições externas favoráveis para as exportações de commodities, ajudou também a especializar pauta exportadora. Dessa forma, a economia parece estar dinamizada por fatores externos que fazem com que a forma de inserção do Brasil na economia internacional tenha uma tendência para ser caracterizada como de periférica, numa visão a partir do arcabouço estruturalista.

Feitas tais considerações sobre o contexto econômico da economia brasileira na última década, na próxima seção será abordado o comportamento do setor industrial.

\section{Alguns aspectos sobre o comportamento do setor industrial no Brasil}

Apesar do bom desempenho experimentado pela economia brasileira na última década, ainda persiste no debate econômico a problemática levantada sobre a capacidade da indústria manufatureira. Como assinalam Fligenspan, Cunha, Lélis (2011), a recuperação da produção e do emprego, em especial em 2010, não foi acompanhada com o crescimento das exportações de manufaturados no comércio internacional; pelo contrário, a economia apresenta um déficit nesse rubro. Esta questão é a que está no centro do debate: o baixo dinamismo industrial que vem se aprofundando desde a implementação do modelo de ajuste estrutural levou a questionar se o Brasil estaria vivenciando um processo de desindustrialização, de doença holandesa ou de reprimarização da pauta exportadora (BRESSER-PEREIRA 2010; FISLOW; BACHA, 2010; OREIRO; FEIJÓ, 2010, entre outros).

Entre os analistas econômicos é consenso que o país passou por uma significativa transformação estrutural e que os ganhos de produtividade alcançados pela indústria na década de 1990 foram resultados dessas importantes mudanças, as quais atingiram principalmente o setor industrial, e para muitos negativamente. Para a corrente teórica "novo-desenvolvimentista”, por exemplo, a economia brasileira já vem passando por um processo de desindustrialização nos últimos 20 anos, em virtude da combinação de políticas que contemplam a abertu- ra financeira, a valorização dos termos de troca e o câmbio apreciado (LOURES; OREIRO; PASSOS, 2006; BRESSER-PEREIRA; MARCONI, 2009); a corrente mais ortodoxa, ao contrário, interpreta as mudanças como positivas. Sustenta que as transformações acontecidas na economia brasileira nas últimas décadas não tiveram efeito negativo sobre a indústria. Esta, sim, foi beneficiada pelas reformas. O que dizer dos benefícios advindos com a apreciação do câmbio real? Afinal, foi a sua valorização que permitiu à indústria incorporar máquinas e equipamentos e introduzir novas tecnologias necessárias à sua modernização e à economia do próprio país (SCHWARTSMAN, 2009).

Todavia, cabe indagar: será que o fenômeno da desindustrialização aconteceu no Brasil, ou ocorreu apenas um rearranjo da estrutura industrial? Para tanto é pertinente expor alguns conceitos daquilo que se entende por desindustrialização. Oreiro e Feijó (2010) salientam que a desindustrialização não necessariamente está relacionada com a "reprimarização" da pauta exportadora e com a chamada "doença holandesa”. Segundo Rowthorn e Ramaswany (1999), o conceito clássico de desindustrialização guarda analogia com a redução do emprego industrial no país ou região. Assim, considerando essa conceituação, os países desenvolvidos teriam passado por um processo de desindustrialização na década de 1970 e os da América Latina na década de 1990, com a implementação do ajuste estrutural. Tregenna (2009) redefiniu de forma mais ampla o conceito. Para ele, desindustrializar constitui uma situação na qual tanto o emprego industrial quanto o valor adicionado da indústria se reduzam como proporção do emprego total e do PIB, respectivamente. Oreiro e Feijó (2010) fazem uma observação importante. Eles não vêem desindustrialização quando a produção do setor industrial está estagnada ou em queda, mas quando esse setor perde importância como fonte geradora de empregos e/ou de valor adicionado para uma determinada economia. Dessa forma, a simples expansão da produção industrial - em termos de quantum - não pode ser utilizada como "prova" da inexistência de desindustrialização.

O processo de desindustrialização no Brasil, vivenciado no período de estudo, deu margem a diferentes interpretações. Às vezes, é utilizada uma conotação negativa para caracterizá-lo, tal como si- 
nônimo de destruição da indústria, ou de alguns de seus ramos mais importantes. No entanto, segundo o informe do IEDI (2005), essa não é a melhor caracterização. De acordo com Singh (1987), desindustrialização consiste no declínio da produção ou do emprego industrial em termos absolutos, ou como proporção do produto ou emprego nacional, processo que é, muitas vezes, caracterizado como uma consequência normal do desenvolvimento econômico bem sucedido em países avançados, estando relacionado com as melhorias do padrão de vida da sociedade (ROWTHORN; RAMASWAMY, 1997).

O Instituto de Estudos de Desenvolvimento Industrial (2005) afirma que ocorreu desindustrialização no Brasil na década de 1990. No entanto, o setor industrial manteve uma significativa diversificação. Apesar de ter perdido alguns segmentos e elos de cadeias decisivas para a industrialização contemporânea, foram preservados setores tecnológicos de ponta, o que de alguma maneira possibilitou ampliar sua produtividade e capacidade exportadora. Dessa forma, o IEDI (2005, p.5) frisava:

Não houve, portanto, uma desindustrialização no sentido de perda irreparável na estrutura industrial do país e em sua capacidade dinâmica, significando isto que a indústria no país conserva requisitos para reerguer-se e reintegrar-se com maior plenitude nas atuais tendências de industrialização dos países de maior dinamismo industrial. Diante das observações acima, julgamos mais conveniente qualificar a desindustrialização ocorrida no Brasil como 'relativa'.

Embora o IEDI afirme que houve desindustrialização no país, ele faz uma ressalva, a de que ela foi relativa. Mesmo relativizando, fica evidente, de certa forma, a condição estrutural que o Brasil vivenciou, devido ao fato de que os setores que ganharam espaço e substituíram a participação da indústria no PIB, não tivessem conseguido fazer o PIB crescer de forma elevada. A desindustrialização relativa ocorrida no Brasil na década de 1990 foi decorrência das políticas macroeconômicas adotadas. Essa desindustrialização relativa está relacionada a mudanças na estrutura industrial, e não com a queda do peso da indústria na participação do PIB. Como se verificou anteriormente, tudo leva a crer que dois são os setores de destaque dessa mudança: a) setores tradicionais, como têxtil e vestuário, e o de material elétrico e eletrônico que tiveram perda de participação na estrutura industrial - eles seriam exemplo de desindustrialização localizada; e b) setores intensivos em recursos naturais apresentaram uma maior especialização produtiva da indústria.

Na Tabela $n^{0} 1$, pode-se observar que o setor de Commodities aumentou sua participação em aproximadamente 6\% entre 1996 e 2007, enquanto a indústria tradicional perde participação em aproximadamente $6 \%$ no mesmo período. 


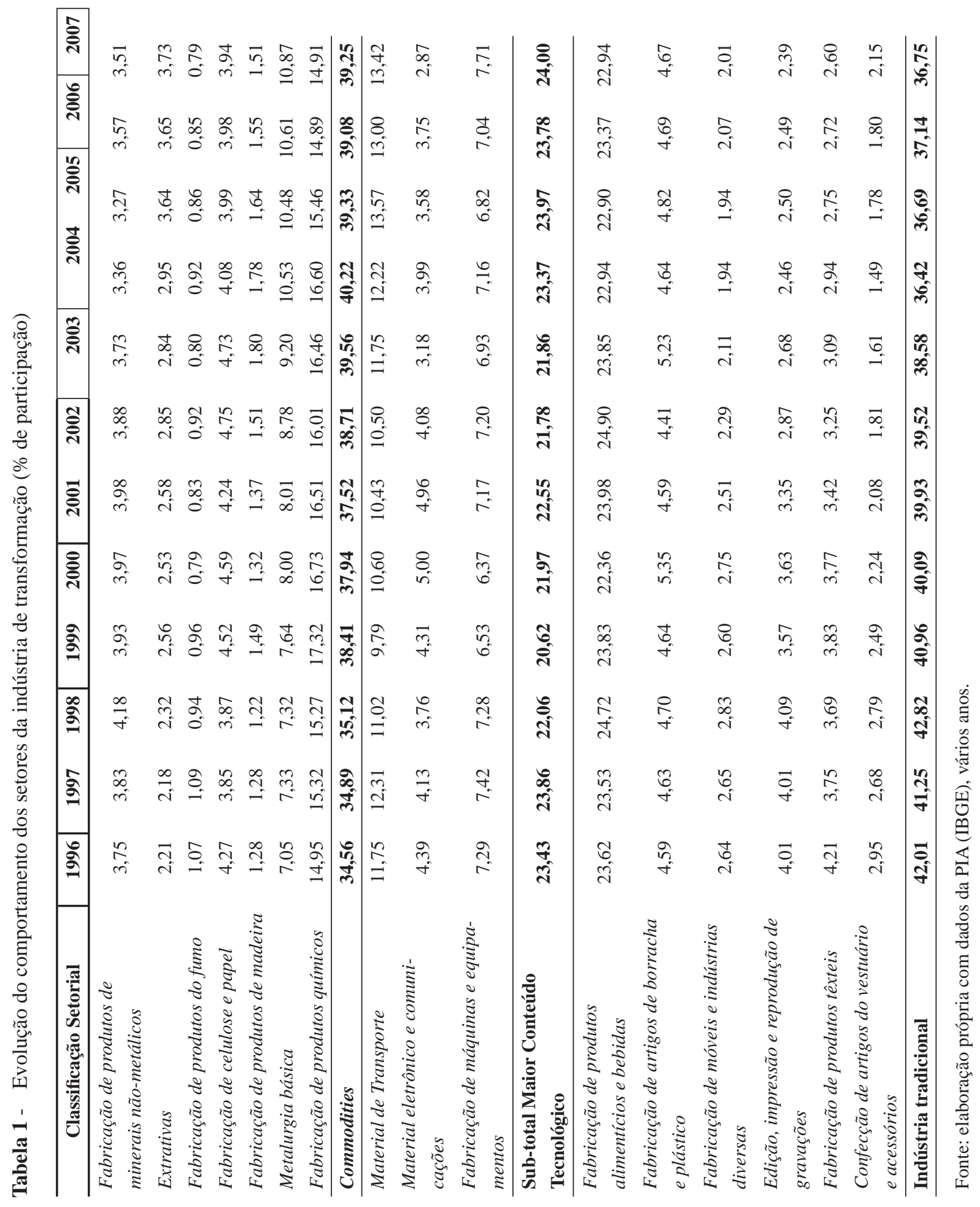


Na Tabela 1 fica claro que o perfil de produção está se especializando na produção de commodities, contestando as teses levantadas na década de 1990 com relação às vantagens que a abertura traria para o up grade da indústria e a pauta exportadora. Verifica-se que, embora o movimento da estrutura produtiva não tivesse uma mudança significativa no período analisado, de acordo com os dados do IEDI (2005), nos anos anteriores, os setores predominantes na matriz industrial do país eram os de maior conteúdo tecnológico. Não custa lembrar que as mudanças estruturais levadas a cabo tiveram um papel fundamentalmente negativo no tocante ao dinamismo da economia brasileira. A conclusão a que se chega, de modo geral, é que o setor industrial brasileiro não avançou durante os anos 1990, persistindo essa característica estrutural na década de 2000, apesar dos indicadores econômicos terem tido uma melhora. Esse comportamento da indústria limita as possibilidades de crescimento, explicando o baixo desempenho da produção.

As informações desta última década corroboram para uma reflexão preocupante, a de que a despeito de todas as mudanças, reformas e ajustes pelos quais o Brasil passou, o país parece ter se afastado um pouco mais do mundo desenvolvido do que dele se aproximado.

Assim, na próxima seção estudaremos como se apresenta a pauta exportadora no período de estudo, mostrando sua especialização em bens de pouco valor agregado combinado com déficits de produtos manufaturados.

\section{A pauta exportadora especializada em com- modities como limitadora do crescimento}

Na última década a balança comercial teve um desempenho bastante positivo, se comparada com a década de 1990. Ela apresentou saldos positivos, como foi mostrado no Gráfico $n^{\circ} 3$, fato que contribuiu para evitar déficit de transações correntes do balanço de pagamentos. Apesar desse panorama alentador para o Brasil, dois fenômenos característicos têm levantado grandes preocupações entre os analistas: a) a dependência dos saldos comerciais dos ganhos de termos de troca; e b) a concentração da pauta exportadora em produtos básicos.

Com relação ao primeiro desses fenômenos, o informe de Conjuntura do IPEA (2012) salienta que se em 2011 os preços das exportações e das importações tivessem permanecido no patamar do ano 2005 - ano no qual o país começa a experimentar os ganhos dos termos de troca - o país enfrentaria déficits comercial. Com relação ao segundo fenômeno, entre os anos de 2005 e 2010 a participação dos produtos básicos na pauta exportadora aumenta de aproximadamente $29 \%$ para $48 \%$, e como contrapartida pode-se observar que os produtos manufaturados perderam participação na pauta de 56\% para 36\%. Este ponto ganha relevância por ser um dos mais debatidos entre os analistas, sendo que alguns levantam a hipótese de que essa situação do comércio se explica em grande parte pela dinâmica dos preços das commodities, que tiveram um ganho de $150 \%$ no período, contra $65 \%$ dos manufaturados (IPEA, 2012). Embora essa dinâmica tenha tido influência no comportamento da pauta exportadora, não é a única causa que explica a especialização em commodities sofrida pela economia. Segundo informe da CEPAL (2012), a elevação dos preços das commodities pode ser relacionada com uma conjuntura atual diferente da observada historicamente, a qual era caracterizada como marcada por forte mudança de curta duração. Entretanto, esse novo padrão de variação dos preços das commodities pode vir a alterar essa tendência histórica por conta da persistência do crescimento da Ásia e da exaustão dos recursos energéticos, dado o padrão tecnológico atual. Nessa nova configuração histórica a China ganha especial destaque, fundamentalmente porque desde meados dos anos 1980 vem se perfilando como hub global, alterando a geografia econômica e o perfil da demanda das matérias primas.

Na verdade, a demanda foi fortemente influenciada pela forma como a China se insere nas cadeias produtivas, ou seja, através de um forte processo de industrialização acompanhada de uma acelerada urbanização que resultou num aumento da demanda de petróleo e metais (CEPAL, 2012), num contexto de oferta relativamente escassa. Outra consequência que todo esse processo teve na economia chinesa foi um aumento da renda, o qual gera significativo aumento da demanda de alimentos e produtos agrícolas. Há um ponto interessante levantado pelos analistas quando se discute a melhora dos preços relativos das commodities, a qual é associada à queda dos preços 
das manufaturas decorrente da participação da China na produção mundial de partes e peças de setores industriais com salários relativamente baixos. Assim, como assinalado pela CEPAL (2012), o deslocamento da produção manufatureira de produtos industriais para regiões com oferta ilimitada de mão-de-obra provoca um efeito deflacionista sobre os preços.

Cabe salientar também como fator importante da variação do preço das commodities os crescentes custos de produção de energia e sua influência direta ou indireta nas outras commodities. Assim, teríamos o encarecimento da produção de energéticos, sobretudo petróleo, com o deslocamento da exploração para áreas com custos mais elevados, com destaque para os campos de águas profundas. Esse aumento de preços torna competitiva a produção de biocombustíveis que, por sua vez, disputam terras agricultáveis com os alimentos e matérias-primas, restringindo a sua produção desses produtos e pressionando a alça dos preços.

Gráfico 5 - Comportamento do comércio de bens manufaturados.

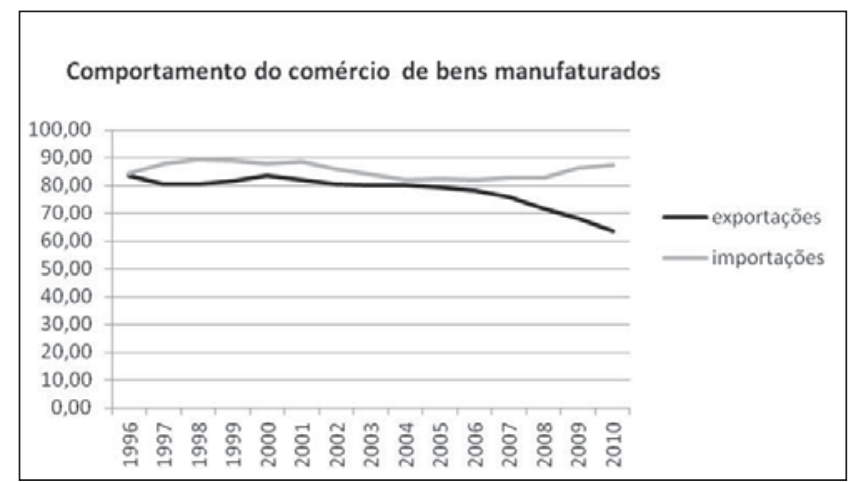

Fonte: elaboração própria com dados do MDIC, 2012.

Apesar do persistente superávit comercial da balança de pagamentos, esta apresenta como característica uma piora do desempenho das vendas externas de manufaturados. Ilustra essa característica o Gráfico $n^{0} 5$, que tem como base as exportações e importações dos setores industriais. Esse fenômeno pode ser explicado por dois fatores: o efeito demanda e o efeito competitividade. Com relação ao primeiro dos fatores, no contexto mundial, houve no período de 2005 a 2010 um aumento do crescimento acumulado das commodities de aproximadamente $64 \%$ contra 36\% das exportações de manufaturados (IPEA, 2012). No entanto, seria pouco desejável atri- buir o fraco desempenho das exportações industriais só ao comportamento da demanda mundial, embora, é claro, esse fator não possa ser desprezado.

Quanto ao efeito competitividade, este pode ser associado à política cambial e a fatores estruturais. Com relação a esses fatores, pode-se dizer que os problemas estruturais da economia brasileira estariam inseridos no bojo do conjunto de políticas de corte neoliberal aplicados na década de 1990 - modelos de ajuste estrutural -, que tiveram como objetivo a estabilização da economia através do Plano Real. Como apresentado na seção 1, o país apresentou uma nova configuração macroeconômica com pífio desempenho dos investimentos (FBKF) nos últimos vinte anos (ao redor de 18\% do PIB), o que limita qualquer tipo de expansão das exportações de manufaturados. Como levantado pelo IPEA (2012), o país não foi capaz de combinar o crescimento do produto junto com exportações de manufaturados devido à reduzida taxa de investimento associada a duas restrições fundamentais: a manutenção de taxas baixas de inflação com valorização cambial. Assim, evidencia as limitações que o crescimento apresenta, porque o país procura manter alta a taxa de crescimento do produto, mas esta não é acompanhada de um movimento paralelo na expansão dos investimentos. Nesse sentido, na visão keynesiana os investimentos são a peça-chave da manutenção da demanda agregada; por isso, na medida em que não se realizam, podem dar lugar ao surgimento de déficits em transações correntes, através do aumento dos importados.

Como podemos observar na seção 2, depois da aplicação das medidas de ajuste estrutural a indústria sofre uma reconfiguração com especialização em setores de extração de recursos naturais. Isso não é mais do que resultado da combinação de política monetária com juros altos com câmbio valorizado, que impedem a expansão do setor produtor de bens industriais comercializáveis como também dos investimentos produtivos.

O padrão de crescimento vigente desde a década de 1990 estabelece limites claros às exportações de manufaturados. Há na atualidade uma série de fatores que também restringem o desempenho favorável da indústria e das exportações de manufaturados: baixa taxa de investimentos, aumento dos preços das commodities, valorização da taxa de câmbio, 
etc. Tais restrições nos levam a debater e questionar como vislumbrar um novo caminho para o desenvolvimento, porque se persistirem essas características a economia brasileira não conseguirá sair do modelo de crescimento stop and go.

\section{Considerações finais}

Entre as teses da década de 1990 havia as que advogavam as vantagens da abertura comercial como forma de gerar na economia o up grade da pauta exportadora. No entanto, o resultado dessas políticas não encontra correlação nem com o desempenho do crescimento nem com a dinâmica do setor externo, concentrado em commodities e com saldo deficitário de manufaturados.

O crescimento recente não se afastou da linha adotada na década de 1990, caracterizado como de stop and go. Além disso, a única variável que apresentou dinamismo na última década foi a referente às exportações, as quais encontraram no contexto internacional condições favoráveis ao seu aumento, especialmente para o comércio de commodities, levando o país a uma especialização que pode ser caracterizada como regressiva. Embora nesta última década o desempenho apresente uma performance dos indicadores econômicos melhores do que na década de 1990, o modelo de desenvolvimento atual levanta muitos questionamentos.

Um deles relaciona-se à dependência da economia brasileira de fatores externos, contexto internacional puxado pela demanda chinesa de matérias primas e produtos de alta intensidade de recursos naturais. Essa demanda foi a que puxou o crescimento do país, enquanto as exportações de bens manufaturados tiveram uma queda de participação no total de exportações. O ciclo de preços favoráveis das commodities inverte a lógica tradicional do passado, que condenava os países exportadores desses bens a um crescimento sujeito à restrição do balanço de pagamento. No período de estudo, o saldo da balança comercial apresentou-se superavitário, no entanto com déficit nos bens manufaturados. É verdade que a demanda chinesa transforma-se numa fonte de crescimento viável das exportações brasileiras, gerando um grande estimulo que não deve ser desprezado. Pelo contrário, poderia ser um caminho tratar de aproveitar esse contexto favorável para o comércio das commodities brasileiras de uma maneira mais aguçada e inovadora, para traçar uma nova direção na senda do desenvolvimento.

Outra questão está relacionada com o processo de desindustrialização, que chama para um debate mais profundo, que não se esgota em estudar a evolução na composição estrutural do PIB ou do emprego. É necessário encontrar as causas concretas do processo de desindustrialização e compará-lo com a tendência esperada da mudança estrutural, verificar quais os fatores e condicionantes que afastaram a economia brasileira desse caminho.

Muitos autores chamam a atenção para a mudança da inserção na economia internacional, considerando como fundamental a introdução de bens mais diferenciados e intensivos em tecnologia, com maior valor agregado. Essa seria uma maneira de acrescentar maior dinamismo à pauta exportadora, para que possa contribuir de forma mais dinâmica na taxa de crescimento da economia. No entanto, essa "receita" - que parece até obviamente conhecida não seria suficiente se também não se criassem políticas, programas e instrumentos que contemplem o investimento, a produção, a indústria e a tecnologia.

Por outro lado, a política de desenvolvimento do Brasil não deveria abrir mão do que foi uma característica do país dentro da região da América Latina, haja vista a diversificação industrial e a integração das cadeias produtivas. Ao se conservar essa diversidade junto a uma nova política industrial e tecnológica, o país poderia se desenvolver com base em uma consolidação da produção mais competitiva.

\section{Referências}

BRASIL. Ministério do Desenvolvimento, Indústria e Comércio Exterior. Disponível em: <www.mdic.gov.br>. Acesso em: junho 2010.

Presidência da República Federativa do Brasil. Ipeadata. Disponível em: <www.ipeadata.gov.br>. Acesso em: junho 2010.

BRESSER-PEREIRA, L; MARCONI, N. Doença holandesa e desindustrialização. Valor Econômico, 25.11.2009.

Brasil vive desindustrialização. Disponível em: <http://www1.folha.uol.com.br/fsp/mundo/ft2908201011. htm>. Acesso em: 30 agosto 2010.

CARNEIRO, Ricardo. A supremacia dos mercados e a política do governo Lula. São Paulo: Editora Unesp, 2006. 
CEPAL - Comissão Econômica para América Latina. Commodities, choques externos e crescimento: reflexões sobre América Latina. Série 117 - Macroeconomía del desarrollo, Santiago de Chile, 2012

FLIGENSPAN, F.; CUNHA, A.; LELIS, M. O desempenho da indústria de transformação nos anos 2000. In: ANPEC, 39, 2011. Anais... Foz do Iguaçu, 6 a 9 dezembro, 2011.

FONSECA, R., CARVALHO, M., POURCHET, H. A orientação externa da indústria de transformação brasileira após a liberalização comercial. Rio de Janeiro: (Texto para Discussão n. 135), FUNCEX, 1998.

HAGUENAUER, L., MARKWALD, R., POURCHET, H. Estimativas do valor da produção industrial e dos coeficientes de exportação e importação. Rio de Janeiro: FUNCEX, 1997.

IEDI - Instituto de Estudos para o Desenvolvimento Industrial. Ocorreu uma desindustrialização no Brasil? Disponível em: <http://www.iedi.org.br/admin_ori/pdf/ 20051129_desindustrializacao.pdf $>$. Acesso em: novembro 2005

IPEA - Instituto de Pesquisa Econômica e Aplicada. Conjuntura em Foco, n.17, ano 4, fevereiro de 2012.

KUPFER, D; CARVALHO, L. A transição da indústria brasileira: da diversificação para a especialização. Disponível em: <www.ie.ufrj.br/datacenterie/pdfs/seminarios/ .../texto3010.pdf>. Acesso em: maio, 2010.

MATTOS, Fernando. Retrospectiva histórica del proceso de globalización financiera.

Revista Investigación Económica, v.60, n. 233, p.113-147, jul./set, 2000.

MOREIRA, M., CORREA, P. Abertura comercial e indústria: o que se pode esperar e o que se vem obtendo, Textos para Discussão n.49. Rio de Janeiro: BNDES, 1997.

OREIRO, J. L; FEIJÓ, C. A. Desindustrialização: conceituação, causas, efeitos e o caso brasileiro. Revista de Economia Política, v.3 n.2 São Paulo, abr./jun. 2010.

PAULANI, Leda. Brasil delivery. São Paulo: Editorial Boitempo, 2008.

PRATES, Daniela Magalhães. Os limites da inserção comercial da economia brasileira. Revista de Economia Política Internacional: Análise Estratégica. n.1, jul/set. 2004.

RODRIK, DANI. Industrial policy for the twenty-first century. John H. Kennedy School of Government, Harvard University (2004). Disponível em: <www.ksg.harvard.edu/ rodrik>. Acesso em: maio, 2010.

ROWTHORN, R; RAMASWANY, R. Growth, trade and deindustrialization. IMF Staff Papers, v.46, n.1,1999.
SINGH, A. Manufacturing and de-industrialization. In: EATWELL, J.; MILGATE, M.; NEWMAN, P. (Eds.). The new palgrave: a dictionary of economics. London: The Macmillan Press, 1987.

TREGENNA, F. Characterizing deindustrialization: an analysis of changes in manufacturing employment and output internationally. Cambridge Journal of Economics, v.33, 2009.
Recebido em: 6 de agosto de 2012 Aceito em: 17 de setembro de 2012 